\title{
DIGITAL TRANSFORMATION IN THE OIL AND GAS SECTOR DURING COVID-19 PANDEMIC
}

\author{
Burkan Hawash*
}

Faculty of Information Science and Technology, Universiti Kebangsaan Malaysia, Malaysia

\author{
Yousef I Abuzawayda*
}

Misurata University, Libya

Umi A Mokhtar

Faculty of Information Science and Technology, Universiti Kebangsaan Malaysia, Malaysia

\section{Zawiyah M Yusof}

Faculty of Information Science and Technology, Universiti Kebangsaan Malaysia, Malaysia

\section{Muaadh Mukred}

Faculty of Information Science and Technology, Universiti Kebangsaan Malaysia, Malaysia

*Corresponding Author

\begin{abstract}
The COVID-19 pandemic is triggering unusual worldwide health and economic crisis with critical circumstances caused many consequences. The continuous COVID19 pandemic has struck every industry, yet the one industry that has tolerated the tremendous shots is the Oil and Gas $(O \& G)$ industry. Various lockdowns impacted projects, with some put on hold as the world battled the spread of the disease. This article discusses the effect of COVID-19 pandemic on O\&G sector digital transformation (DT). In particular, this article delivers trustworthy thoughts and reflections on whether O\&G organizations expedite their DT during COVID-19 outbreak. The aims of this paper could be invaluable to newly created organizations which intend to rely on information systems or get hold of opportunities in transforming their operational process into digital.
\end{abstract}

Key words: COVID-19, Digital Transformation, Oil and Gas, Electronics Processes, Business Continuity.

Cite this Article: Burkan Hawash, Yousef I Abuzawayda, Umi A Mokhtar, Zawiyah M Yusof and Muaadh Mukred, Digital Transformation in the Oil and Gas Sector during Covid-19 Pandemic, International Journal of Management, 11(12), 2020, pp 717-724.

http://iaeme.com/Home/issue/IJM?Volume=11\&Issue=12 


\section{INTRODUCTION}

COVID-19 has attacked China and spread around the world which causes several changes in the economic and health system in many countries. The universal COVID-19 pandemic stopped businesses weather temporarily or permanently, put economies at risk, O\&G unprecedented demand drop and a global humanitarian crisis, paused people lives and has caused widespread interruptions and chaos since the November 2020 ( $\AA$ gerfalk, Conboy, \& Myers, 2020; Fletcher \& Griffiths, 2020) . For example, the governments in most countries decided to control the movement of people and locked down all businesses except for the emergencies and slow or stop physical operations. O\&G Organizations need to continue their operations and guarantee business continuity, electronics and digital technologies could be a good choice to ease the operations from home. DT has allowed businesses to preserve activities and shifting supply and demand digitally (Priyono, Moin, \& Putri, 2020).

The novel COVID-19 outbreak has initiated histrionic environmental fluctuations that persuade governments and organizations to adopt electronic and digital technologies on a widespread measure and under stressful circumstances (Priyono et al., 2020). There are increasing of use electronic and digital systems for online purposes by many organizations particularly conducting conferences and teaching in schools and high educational institutions, working remotely in telecommunications companies and some businesses that can perform activities online including O\&G organizations. There is a need to implement new technology to support the business during lockdown period. It is literally indicated by many studies that businesses are becoming more digital which means they are using new digital technologies such as Blockchain, electronic records management system(ERMS), cloud computing, electronic health records system (EHRS), Internet of Things (IoT), big data, artificial intelligence (AI) robotics, and other new electronic and digital technologies that matching the needs of O\&G sector (Dey, Al-Karaghouli, \& Muhammad, 2020; Soto-Acosta, 2020).

In this article, DT means to transform operational activities, telecommunications and activities into electronics and digital ones (Bican \& Brem, 2020; Gaid, Alhakimi, Alasadee, \& Ali, 2019). Therefore, an electronic and digital businesses are proper for the O\&G corporations which do not manage important operations, processes and relationships with its personnel and third-party organization through electronics or digital technology (Soto-Acosta, 2020). By using digital technology, O\&G corporations are shifting the rules of the businesses, which should be become more worldwide and digital. Digitalization was influenced all the characteristics of the current business from creation and production until consumption (Muaadh, 2017). Thus, DT is portrayed by the utilization of developing and habitually changing advanced advancements to tackle explicit issues. DT has rapidly turned all activities in organizations around the world, particularly during the pandemic of COVID-19 into digital (Butt, 2020).

Simultaneously, most of users can access to every authorized process in organization and resume activities from home via DT. The digitization has developed business from a geographically constrained to real global businesses in addition to ease operations through on line procedures. Moreover, it helps several organizations to conduct operations and services digitally (B. Hawash, Asma mokhtar, Yusof, Mukred, \& Ali, 2020; Burkan Hawash, Mokhtar, \& Yusof, 2019). With regard to manufacture and invention, electronics and digital technologies have influenced businesses particularly industries in different ways. Digital technologies have moved firms from one production to another with new or renewed worth applications (Malkin, 2020). In addition, when organizations have applied digital technologies their businesses would be developed technically and traditional businesses are becoming more and more systematic. 
This article focuses on how DT of O\&G sector is expedited during COVID-19 pandemic. In particular, this article discusses the effect of COVID-19 pandemic in processes of O\&G organizations and the need to turning all activities into digital. The current article discusses the DT in organizations due to the COVID-19 pandemic, the influence of the DT and the novel COVID-19 pandemic on the upcoming business of O\&G sector. Lastly, this article proposes a conceptual model for the DT in the O\&G sector with recommends the benefits that organizations can gain from DT initiative.

\section{DT IN O\&G SECTOR DUE TO COVID-19 PANDEMIC}

Wherever we look nowadays, many information technology developments including digital technologies is categorized as DT. In O\&G sector, digitalization can be a source of transformational change, but there are a number of challenges that need to be overcome to realize its full potential for both business and wider society (Mingaleva, Shironina, \& Buzmakov, 2020). The actuality is that several tasks or activities that continuously created in organization are digital, but not transformational. Many firms in $O \& G$ sector are using video and audio conference to conduct important meeting and share new ideas between management and personnel. The transformation of processes in organization to digital could be difficult and is not easy task to be changed from manual to electronic or digital (Gaid, Qaid, Ameer, Qaid, \& Ahmed, 2019).

The ongoing development in digital technologies is significant as it makes permanent competing advantage for those industries who adopt and implement it. DT provides O\&G organizations with tools, for example, networking of multiple systems, sensors, and analytical models, to update planning and operational standards (Abuzawayda, Yusof, \& AZIZ, 2013; Priyono et al., 2020). They deliver new oilfield insights by applying big data to decrease operating costs, increase production, and make a better decision. This could be considered DT, which might be valuable for the business to continue operations during COVID-19 pandemic. For instance, O\&G sector can use DT to expedite businesses' processes through digital systems during this pandemic

In the recent years, the $\mathrm{O} \& \mathrm{G}$ industry has adopted advanced machinery aimed at improving the operations and drilling process. It also has been using information technology applications for managing and organizing data being generated from the front-end operations. At present, some of the leading industry players are even implementing new-age technologies to re-imagine business processes and drive actionable insights from the available data pool. The industry is aware and accepts the fact that the application of new-age technologies, such as AI, IoT and Big Data analytics, leads to faster and more accurate operational decision making. The adoption of advanced IT applications is set to play a key role in bridging the gap between upstream, midstream and downstream processes in the $O \& G$ industry using historical data analyses in real-time (Author). In the digital technology, DT is changing manual processes into digital and creating new online domain to achieve work remotely (Bican \& Brem, 2020; Soto-Acosta, 2020). DT obviously involves the use of digital technologies to make important changes in the O\&G sector operations. The COVID-19 pandemic expedites the DT in several organizations including O\&G sector. (Fletcher \& Griffiths, 2020; Mukred, Yusof, Alotaibi, Asma'Mokhtar, \& Fauzi, 2019).

Therefore, although O\&G sector has implemented many information systems and evolving DT which offered an invaluable and valued solution during COVID-19 pandemic, it is still using manual processes. To be successful despite these current market conditions, O\&G organizations recognize the necessity of digital technology instead of physical operations (Daneeva, Glebova, Daneev, \& Zvonova, 2020; Steiber, Alänge, Ghosh, \& Goncalves, 2020). Ultimately, companies that have not yet embraced digital implementation 
throughout the organization can no longer afford a cautious approach; the value digital tools deliver is critical for survival in today's price environment (Abuzawayda, Zawiyah, \& Ab Aziz, 2013).

Accordingly, the O\&G sector should prepare new strategy to be applied during COVID19 pandemic, DT also should include four additional important principles as illustrated in Fig. 1. The relevance of DT makes new alignments with customers and users need during and post-COVID-19 easier. DT should be relevance for recovery and in the current situation. The O\&G sector has to consider what customers and users will expect from its organization now and in the future under any recovery setup. On the other hand, sustainability in DT will make processes and operations in O\&G organization deliver sustainable and tangible services during lockdown period which considered value in the short-term, improvement in doing activities to the future of users, and shareholders

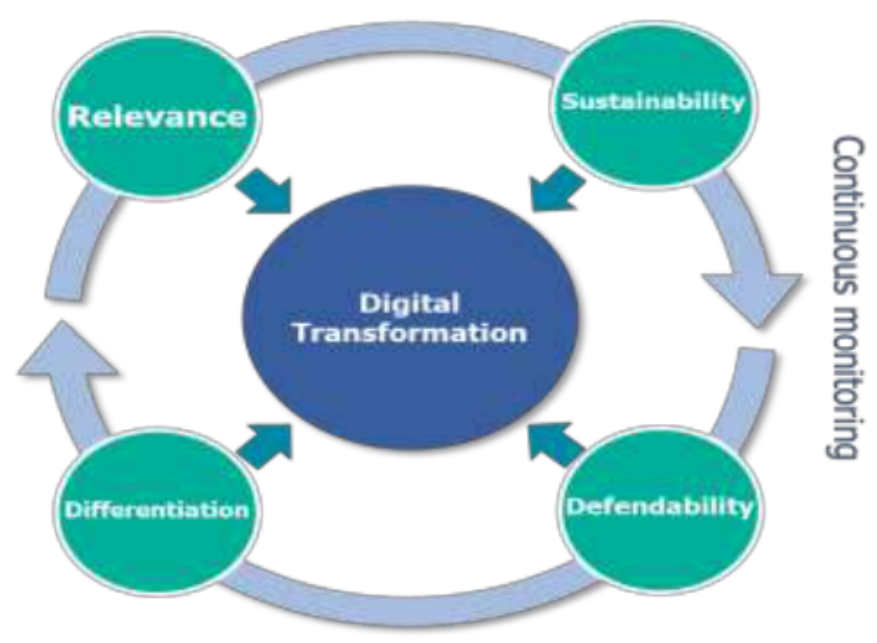

Figure 1 Principles affecting DT post COVID-19

Accordingly, the DT increases the defendability of O\&G sector which has led to continue working from home and to recognizing COVID impact and action. Strategies are should set in consideration of the impact of COVID-19 on processes and help in minimizing the risk. The strategy is playing an important role to support business continuity and has led very quickly to return on investment.

Many O\&G organizations have created policies and strategies that support differentiation as a necessary diversity for marketing their businesses globally during pandemic and setting businesses apart from the market. O\&G organizations should consistently to find new sources of differentiation to stay relevant, "sticky" to their consumers and ahead of their competition. In DT era, it is the first movers and very fast followers that gain a huge advantage over changing processes into digital.

The DT taking the long-term view now with long lockdown situation which will help O\&G business resilience in the face of future threats and assist in delivering new growth. As a resource substantial industry, the oil and gas area has been in critical need of advanced tasks for quite a long time - yet the expense and trouble of appropriately actualizing a methodology in such an equipment concentrated climate has eased back advancement previously. DT is not, at this point an alternative that a few organizations are deciding to seek after - it is quickly getting difficult to work without methodologies set up (Eroğlu, 2020; Shen, Fu, Pan, Yu, \& Chen, 2020). 


\section{INFLUENCE OF DT ON O\&G SECTOR WORK DURING AND AFTER THE COVID-19 PANDEMIC}

The COVID-19 crisis has pressed the reset button with significant implications for every industry by challenging forward operating assumptions. According to the (Priyono et al., 2020) the comprehensive DT is the contemporary technology that support and develop economy, however, many organizations either are not familiar with or ignoring its useful influence on their businesses. A studies by (Gasser, Ienca, Scheibner, Sleigh, \& Vayena, 2020; Priyono et al., 2020) stated that "despite the fact that digital approaches to management are in demand, many companies are not ready for their implementation". Some experts have described the DT in O\&G organizations as s new digital practice applied to processes in order to improve work during any emergency event (Dey et al., 2020). According to many IT and O\&G experts, DT influences all kinds of O\&G business such as production and exploration, petroleum marketing companies, and oil services corporations.

In the O\&G sector current situation caused by the COVID-19 pandemic, O\&G organizations have been adopting DT to follow the lockdown instructions and acclimate to work in the new situation. The O\&G sector could adapt to a potential of new digital technologies such as AI, robotics to replace manual repeated tasks with electronics. O\&G organizations should be aware that influencing individuals' efficiencies when using new technology is still not improved and in its initial phase (R. Chetty, J. Friedman, N. Hendren, \& M. Stepner, 2020; R. Chetty, J. N. Friedman, N. Hendren, \& M. Stepner, 2020). Therefore, it is important to replace manual processes with electronic and digital ones that can be utilized to permit representatives to accomplish their work more efficiently and safely during COVID19 (Levit, 2018). The current situation makes personnel in the O\&G sector cope with DT to keep business running and perceive new technologies.

The new challenges have created opportunities for organizations and employees to develop technical and human skills in terms of digital and electronic transformation and safe many occupations. Thus, whether permanent employees or those whose are working on business contracts as freelancers need to drive mutate their career to satisfy with new work processes that are transformed digitally. Digitization is not substitute employees' jobs but mutates activities and operational processes, which can be done through existing employees (Xing 2020, Reese 2018, Author et al. 2020).

Although lockdown led stay-at-home, users have remained connected for work and business has continued in a different way compared to the normal situation. For organizational use of DT technology, personnel in O\&G sector might have faced different challenges in relation to ease of use, as technical supports may not be same as what they normally were (Hawash et al. 2021). The IT support team are also working from home to support the organization team in how to use new form, download policies, and perform other DT processes (Gasser et al., 2020; Kuklina \& Semkova, 2020). Many organizations have motivated to include the establishment of hardware and software support and online training, to improve their employees' skills in dealing with work from home related technological challenges. Experimental works can examine whether or not these procedures are satisfactory and suitable (Harding et al., 2020; Mustafa, Kar, \& Janssen, 2020). There are possibilities for applying mixed methods research to inspect and investigate the adoption of new digital system during the COVID19 pandemic with a specific concentration on influence of DT on work from home. (Novel, 2020; Papadopoulos, Baltas, \& Balta, 2020).

Furthermore, many employees were lost their jobs due to the COVID-19 pandemic in small businesses while the change to DT in big firms such as O\&G sector play a role to protect the jobs and make it easier to perform activities from home and stayed safe (Weemaes et al., 2020). The O\&G organizations have exposed to a biggest problem due to oil prices 
dropped off however the increasing of oil production remains constant and the operations are continued normally (Iyke, 2020; Yin, Zhang, \& Dong, 2020).

In addition, the need to protect the economy has given growth to the DT this year particularly in O\&G organizations, new initiated companies (startups), universities, big trading firms and telecommunications sector (Meseguer-Martinez, Popa, \& Soto-Acosta, 2020). These firms have taken advantage of DT and continue the businesses most likely normally. Therefore, while DT is developing the business, established new policies and frameworks are needed to protect the data and records in organization during this period (Steiber et al., 2020). It was proven that current situation due to COVID-19 lockdown has facilitated the establishment of electronic and digital works because the organization has performed its business from home using ICT equipment and DT. On the contrary, O\&G organizations were established new digital processes to avoid any interruption that impact business continuity (B Hawash, Mokhtar, Yusof, \& Mukred, 2020).

The impact of DT is allowing O\&G firms connecting to several information sources, both structured and unstructured, allowing the extraction of content from memos, requests files, office documents and many other data types (Daneeva et al., 2020; Wanasinghe et al., 2020). DT unlocks the full potential of organization data, allowing users and management to digitally transform daily activates and get ready to take advantages of new technologies such as machine learning, cloud computing and AI and offers a robust digitalization that can be used to pass information efficiently to organizations machines and for exploration and production workflow integration. In addition to, O\&G sector uses Robotic Drilling Systems (RDS) which is developing an entirely electric and robotic drill surface for rapid, seamless and entirely drilling operations (Hawash, B et al. 2021).

\section{RECOMMENDING AND PROPOSED MODEL}

As a price of oil continue to drop, the O\&G sector is facing strong pressure to improve operations during the pandemic and this can be achieved only by using effective digital system. DT could transform the way people work at home and the industry continues its operation normal. While DT has tremendous potential to benefit O\&G sector, it is still not completely implemented by all organizations to guarantee its full value. To do so, all main leadership in the sector including coordinated regulatory efforts to maximize the value of DT for decision makers to involve in taking action. Successful DT will need cooperation between leaders, and decision makers.

The current article recommends $O \& G$ sector to make digital a priority for running business during COVID-19 and achieving executives' processes. Thus, organization should invest in DT development programs that promote new, digital thinking. Creating a methodical approach for developing policies and framework to guide users when applying DT and/or industrializing new capabilities. This includes decisions about whether to build or buy capabilities, and a digital management approach to scale up technology and digital platforms. The DT can develop comprehensive data standards in O\&G sector. This includes policies related to data sharing and security, and encouraging transparency in operations.

Although COVID-19 is affecting all industries, O\&G sector was impacted variously by business movement with critical contrasts. Therefore, O\&G sector should quickly and automatically produce analytical models (e.g. reservoir models, drilling plans and production profiles) that can analyze bigger, more complex data, and deliver faster, more accurate results, even at a very large scale. By building precise models, O\&G sector has implemented a better DT processes in order to continue working on lockdown situation and performed all kind of business activities. 
Although the industry operations type, all operations and activities of the O\&G sector need to be digitalized such as production daily activities, drilling services, logistics services, human resources and financial processes and other business models. There are many new technologies that corporations can be used to accomplish digitalization and combination of all business activities. The block chain and ERMS enhance the change to digital to create all activities and processes. The blockchain offers an easy way to transfer information and automatically tracks each transaction, it enables users in $O \& G$ organizations to respond to many activities using digital system. There is a need in O\&G sector for automating all tasks that are performing from home in order to reducing operating expenses and cope with new situation. More specifically any confidential administrative paperwork can be transferred digitally and fast.

In the present COVID-19 outbreak situation, O\&G sector should employ DT as significant asset in order to deal with current challenges. The change to new digital status makes organization more confident to work actively from home and avoid any risk can be happened for its personnel and data. The new DT will help top management managing business remotely and conduct all activities with third-party or stakeholders. O\&G Organizations can integrate sites with their digital systems and other electronic records management system for automatic processing. Similarly, organization can connect with users using Microsoft Teams and manage the activities through ERMS.

Accordingly, the success of DT can increase the success of O\&G sector operations from home during COVID-19 pandemic. Therefore, DT converts operations and increases quick and strategic decision-making. This leads to propose a new conceptual model guiding the operations using DT. A proposed conceptual model has been developed to quantify the digitalization's impact on the O\&G sector during COVID-19 pandemic as shown in Fig 2.

The proposed model shows many values that can be performed through DT. The O\&G sector will improve its business during COVID-19 pandemic and keep competitive in the market. The proposed conceptual model controls the processes that must be changed to digital. Organization should set a plan to apply any new system without affecting the normal situation when this pandemic finished. Fig 2 shows that DT controls processes of businesses, strategy plan, leaderships, digital systems, site operations, financial performance and organization value.

The value that O\&G sector will gain is to assess the impact of DT initiatives on oil organizations during COVID-19 and continue businesses safely. The proposed model provides likely value estimates of worldwide O\&G operating profits that were affected during pandemic in 2020, and the contribution that DT can make to organization's users and management. The models added for industry two essentials values: first, value addition, or the potential impact generated by digital initiatives on a sector's operating profits; and second, value migration, or the operating profits that will shift between different businesses during current situation. In addition to, the value that leaderships will gain through using new technologies such as improving employees' skills and protecting confidential data. The value of digitalization estimated in the proposed model is based on existing restrictions. The potential values could be improved if O\&G DT could essentially modify the processes and methods of operations are conducted (e.g. by changing workflows). Leaderships should decide in what way real-time data, decision-making and cooperation will change how they manage their activities of operations. 


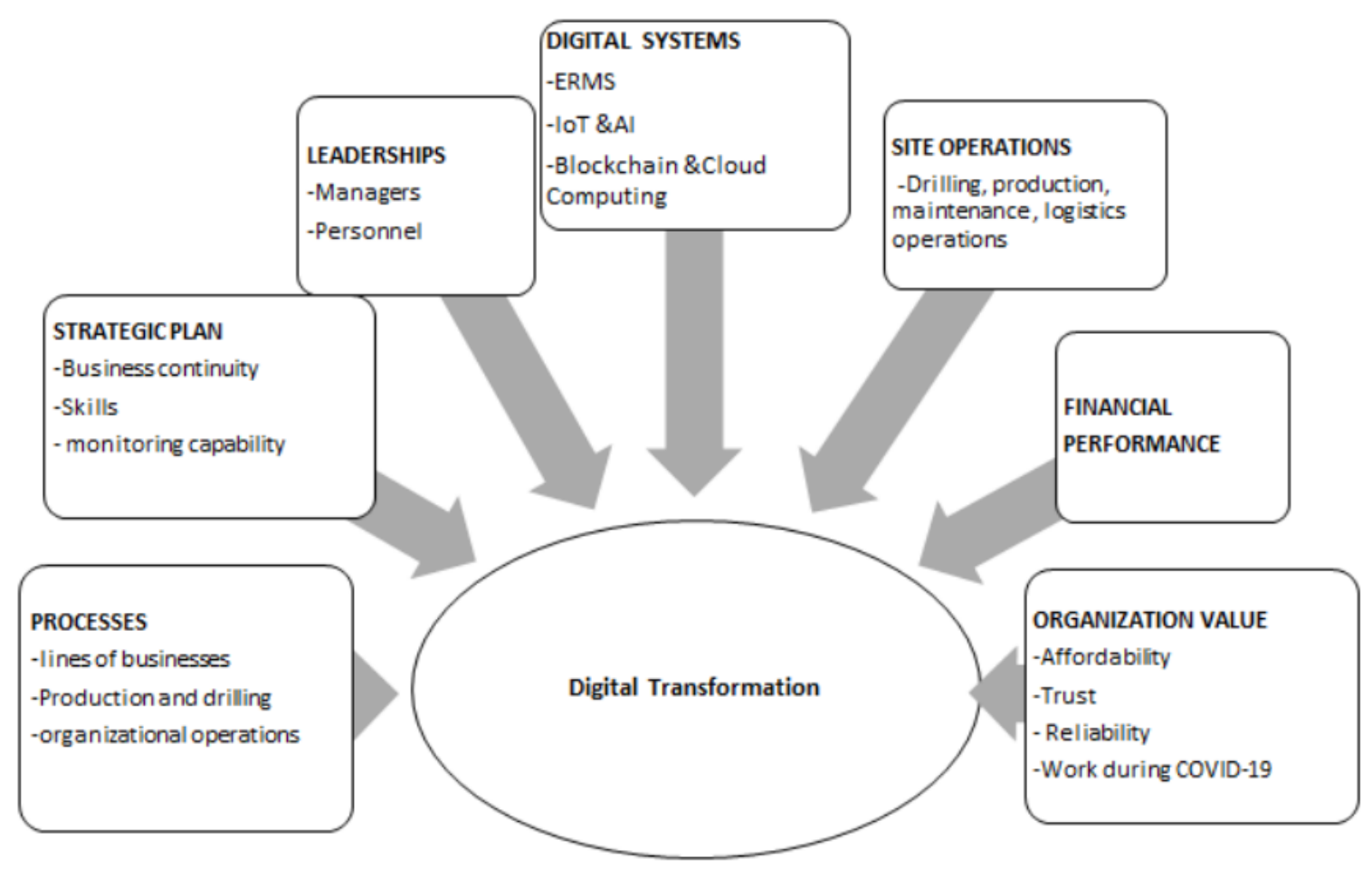

Figure 2 Proposed Conceptual Model

For instance, the proposed conceptual model is creating an important idea in how the DT can add values for the O\&G sector through changing manual or physical work to digital and communicate stakeholders. After the successful implementation of the DT and applied to businesses processes, data should be organized, and the environments should be associated with digital systems, to ensure that the DT yielded the required results for the organization. Thus, the operating processes and techniques should be documented, standardized and a strategic management plan should be developed by the top management to continuously monitor the new process, address the training needs for personal through DT, and identify opportunities for improvements.

\section{CONCLUSION}

While the oil prices continue to hamper margins, the O\&G sector is facing intense pressure to find proper solutions to improve operational efficiencies and continue working during lockdown. There is only one solution in place can help O\&G sector continue businesses during COVID-19 pandemic which is require DT to force O\&G sector to shift most of its operation to digital practices and goes online during the lockdown, so joining some business platforms using DT has been one option to continue operations remotely. DT has many benefits and potential to expedite the operations from home thus protects organization data during and after its implementation. This article addresses the impact of COVID-19 on DT adoption in the O\&G sector and proposes a conceptual framework to guide leadership to get acknowledge about benefits of DT. In conclusion, O\&G sector is accelerating the adoption of DT as the best way to avoid a short-term economic collapse and struggle the COVID-19 pandemic with flexibility. For the O\&G sector to be prepared, DT should be on the strategic agendas of leaderships of organizations, and at the highest level. DT such as any other significant assets needs to be sponsored from top management. This includes creating a strategic vision, requiring financial support, and actively supporting the change-management effort associated with it. 


\section{REFERENCES}

[1] Abuzawayda, Y. I., Yusof, Z. M., \& AZIZ, M. A. (2013). Electronic Records Management in Institutions of Higher Learning in Libya: Adoption of Dirks Model. Journal of Theoretical \& Applied Information Technology, 53(3).

[2] Abuzawayda, Y. I., Zawiyah, M., \& Ab Aziz, M. (2013). Automated Retention Schedules: The Importance of Its Implementation by Universities in Malaysia. Journal of Theoretical \& Applied Information Technology, 54(1).

[3] Ågerfalk, P. J., Conboy, K., \& Myers, M. D. (2020). Information systems in the age of pandemics: COVID-19 and beyond: Taylor \& Francis.

[4] Bican, P. M., \& Brem, A. (2020). Digital Business Model, Digital Transformation, Digital Entrepreneurship: Is There A Sustainable "Digital"? Sustainability, 12(13), 5239.

[5] Butt, J. (2020). A Conceptual Framework to Support Digital Transformation in Manufacturing Using an Integrated Business Process Management Approach. Designs, 4(3), 17.

[6] Chetty, R., Friedman, J., Hendren, N., \& Stepner, M. (2020). The economic impacts of COVID-19: Evidence from a new public database built from private sector data. Retrieved from

[7] Chetty, R., Friedman, J. N., Hendren, N., \& Stepner, M. (2020). How did covid-19 and stabilization policies affect spending and employment? a new real-time economic tracker based on private sector data (0898-2937). Retrieved from

[8] Daneeva, Y., Glebova, A., Daneev, O., \& Zvonova, E. (2020). Digital Transformation of Oil and Gas Companies: Energy Transition. Paper presented at the Russian Conference on Digital Economy and Knowledge Management (RuDEcK 2020).

[9] Dey, B. L., Al-Karaghouli, W., \& Muhammad, S. S. (2020). Adoption, Adaptation, Use and Impact of Information Systems during Pandemic Time and Beyond: Research and Managerial Implications. Information Systems Management, 1-5.

[10] Eroğlu, H. (2020). Effects of Covid-19 outbreak on environment and renewable energy sector. Environment, Development and Sustainability, 1-9.

[11] Fletcher, G., \& Griffiths, M. (2020). Digital transformation during a lockdown. International Journal of Information Management, 102185.

[12] Gaid, A. S., Alhakimi, A. M., Alasadee, M. S., \& Ali, A. A. (2019). Compact and Bandwidth Efficient Multi-band Microstrip Patch Antennas for $5 G$ Applications. Paper presented at the International Conference of Reliable Information and Communication Technology.

[13] Gaid, A. S., Qaid, O. A., Ameer, M. A., Qaid, F. F., \& Ahmed, B. S. (2019). Small and Bandwidth Efficient Multi-band Microstrip Patch Antennas for Future $5 G$ Communications. Paper presented at the International Conference of Reliable Information and Communication Technology.

[14] Gasser, U., Ienca, M., Scheibner, J., Sleigh, J., \& Vayena, E. (2020). Digital tools against COVID-19: taxonomy, ethical challenges, and navigation aid. The Lancet Digital Health.

[15] Harding, D., Kadiyono, A. L., Hafiar, H., Mamun, T. N., Wibowo, H., Nugraha, Y., \& Siswadi, A. G. P. (2020). Readiness of Technology Adaptation towards Digital-Based Entrepreneurship. International Journal of Entrepreneurship, 24(1).

[16] Hawash, B., Asma 'mokhtar, U., Yusof, Z. M., Mukred, M., \& Ali, W. (2020). Intention to adopt electronic records management system in the oil and gas sector in Yemen. International Journal of Advanced Trends in Computer Science and Engineering, 9(5), 6959-6971. doi:10.30534/ijatcse/2020/13952020 
[17] Hawash, B., Mokhtar, U. A., \& Yusof, Z. M. (2019). The primarily study of Electronic Records Management System (ERMS) for Yemen Oil and Gas Corporation (YOGC) Subsidiaries. Paper presented at the 2019 International Conference on Cybersecurity (ICoCSec).

[18] Hawash, B., Mokhtar, U. A., Yusof, Z. M., \& Mukred, M. (2020). The adoption of electronic records management system (ERMS) in the Yemeni oil and gas sector: Influencing factors". Records Management Journal, https://www.emerald.com/insight/search?q.

[19] Hawash,B, Mokhtar, U and Yusof, Z. "Users acceptance of electronic record management system in the context of the oil and gas sector in Yemen: an application of ISSM-TAM." International Journal of Management and Enterprise Development 20, no. 1 (2021).

[20] Iyke, B. N. (2020). COVID-19: The reaction of US oil and gas producers to the pandemic. Energy Research Letters, 1(2), 13912.

[21] Kuklina, E., \& Semkova, D. (2020). Digital Technologies as a Key Tool to Increase the Efficiency of the Russian Oil and Gas Industry in Modern Conditions of Functioning. Administrative Consulting.

[22] Levit, A. (2018). Humanity Works: Merging technologies and people for the workforce of the future: Kogan Page Publishers.

[23] Malkin, A. (2020). The made in China challenge to US structural power: industrial policy, intellectual property and multinational corporations. Review of International Political Economy, 1-33.

[24] Meseguer-Martinez, A., Popa, S., \& Soto-Acosta, P. (2020). The instrumentation of science parks: an integrative framework of enabling factors. Journal of Intellectual Capital.

[25] Mingaleva, Z., Shironina, E., \& Buzmakov, D. (2020). Implementation of Digitization and Blockchain Methods in the Oil and Gas Sector. Paper presented at the International Conference on Integrated Science.

[26] Mukred, M (2017). Framework for Electronic Records Management System Adoption in The Higher Professional Education In Yemen. Universiti Kebangsaan Malaysia (UKM).

[27] Mukred, M., Yusof, Z. M., Alotaibi, F. M., Asma'Mokhtar, U., \& Fauzi, F. (2019). The key factors in adopting an electronic records management system (ERMS) in the educational sector: A UTAUT-based framework. IEEE Access, 7, 35963-35980.

[28] Mustafa, S. Z., Kar, A. K., \& Janssen, M. (2020). Understanding the impact of digital service failure on users: Integrating Tan's failure and DeLone and McLean's success model. International Journal of Information Management, 53, 102119.

[29] Novel, C. P. E. R. E. (2020). The epidemiological characteristics of an outbreak of 2019 novel coronavirus diseases (COVID-19) in China. Zhonghua liu xing bing xue za zhi=Zhonghua liuxingbingxue zazhi, 4l(2), 145.

[30] Papadopoulos, T., Baltas, K. N., \& Balta, M. E. (2020). The use of digital technologies by small and medium enterprises during COVID-19: Implications for theory and practice. International Journal of Information Management, 102192.

[31] Priyono, A., Moin, A., \& Putri, V. N. A. O. (2020). Identifying Digital Transformation Paths in the Business Model of SMEs during the COVID-19 Pandemic. Journal of Open Innovation: Technology, Market, and Complexity, 6(4), 104.

[32] Shen, H., Fu, M., Pan, H., Yu, Z., \& Chen, Y. (2020). The impact of the COVID-19 pandemic on firm performance. Emerging Markets Finance and Trade, 56(10), 2213-2230.

[33] Soto-Acosta, P. (2020). COVID-19 Pandemic: Shifting Digital Transformation to a HighSpeed Gear. Information Systems Management, 1-7. 
[34] Steiber, A., Alänge, S., Ghosh, S., \& Goncalves, D. (2020). Digital transformation of industrial firms: an innovation diffusion perspective. European Journal of Innovation Management.

[35] Wanasinghe, T. R., Gosine, R. G., James, L. A., Mann, G. K., de Silva, O., \& Warrian, P. J. (2020). The Internet of Things in the Oil and Gas Industry: A Systematic Review. IEEE Internet of Things Journal.

[36] Weemaes, M., Martens, S., Cuypers, L., Van Elslande, J., Hoet, K., Welkenhuysen, J., Jeuris, K. (2020). Laboratory information system requirements to manage the COVID-19 pandemic: a report from the Belgian national reference testing center. Journal of the American Medical Informatics Association.

[37] Yin, S., Zhang, N., \& Dong, H. (2020). Preventing COVID-19 from the perspective of industrial information integration: Evaluation and continuous improvement of information networks for sustainable epidemic prevention. Journal of Industrial Information Integration, $19,100157$. 